\title{
Minimal Flow Application in Single Lung Ventilation
}

\author{
Fatih Dogu GEYIK*, Yucel Yuce, Gulten Arslan and Kemal Tolga Saracoglu \\ Department of Anaesthesiology and Reanimation, University of Health Sciences Kartal Dr. Lutfi Kirdar \\ Education and Research Hospital, Turkey
}

*Corresponding author: Fatih Dogu GEYIK, MD, Specialist, Department of Anaesthesiology and Reanimation, University of Health Sciences Kartal Dr. Lutfi Kirdar Education and Research Hospital, Kartal, Istanbul, Turkey, Tel: 00-90-216-45830-00, Fax: 00-90-216-352-00

\begin{abstract}
Objective: We aimed to investigate the effect of low and minimal flow desflurane anesthesia on hemodynamic parameters, cerebral oxygenation, blood gas values, and gas consumption amounts in patients undergoing Single Lung Ventilation (SLV).

Methods: 60 ASA I-III patients scheduled for elective thoracic surgery with single lung ventilation were randomly divided into 2 groups as low-flow (LF) and minimal flow (MF). After applying $4 \mathrm{~L} / \mathrm{min}$ of fresh gas flow for the first 10 minutes in both groups, $1 \mathrm{~L} / \mathrm{min}(80 \%$ oxygen $+20 \%$ air $)$ with $4-6 \%$ desflurane to LF group $(n=30)$ and $0.5 \mathrm{~L} / \mathrm{min}$ ( $80 \%$ oxygen $+20 \%$ air) with $6-8 \%$ desflurane to MF group $(n=30)$ was applied. The patient was set with the Dräger Perseus anesthesia device to have a tidal volume of 4-6 ml/ $\mathrm{kg}$, respiratory frequency of $16-18 / \mathrm{min}$, and an Inspiration: Expiration (I:E) ratio of 1:2 [End tidal carbondioxity $\left(\mathrm{EtCO}_{2}\right)$ $35-45 \mathrm{mmHg}$.
\end{abstract}

Results: There was no significant difference between the groups in terms of demographic data, single lung ventilation (SLV), and operation duration, desflurane intake, and consumption amount, perioperative heart rate, systolic and diastolic arterial pressure. $\mathrm{SpO}_{2}, \mathrm{EtCO}_{2}$ and cerebral oximetry mean values were found to be lower in the minimal flow group. $\mathrm{pH}, \mathrm{HCO}_{3}$, peripheral oxygen saturation $\left(\mathrm{SpO}_{2}\right)$, carboxyhemoglobin, and lactate values were high in the minimal flow group and the $\mathrm{PCO}_{2}$ value was low.

Conclusion: Low and minimal flow anesthesia applications can be applied safely in patients with SLV, especially with cerebral oximetry and blood gas monitoring, with an anesthesia device with sufficient equipment and close monitoring, and even increase patient safety due to the need for closer monitoring of the patient.

\section{Keywords}

Single lung ventilation, Minimal flow anesthesia, Cerebral oximetry, Blood gas

\section{Introduction}

Interest in low fresh gas flow anesthesia methods has gradually increased over the decades. The high standard of anesthesia machines, the presence of monitors that analyze the anesthetic gas composition continuously and in detail, and the increase in knowledge on the pharmacodynamics and pharmacokinetics of inhalation anesthetics have greatly facilitated the safe administration of low-flow anesthesia. The reasons for anxiety about low fresh gas flow techniques are that the anesthesiologist does not know the technique, the dose of anesthetic gases for these techniques, and the uncertainty about the suitability of anesthesia machines.

Terminology for low-flow anesthesia techniques can be based on the respiration rate or fresh gas flow rate. The most important factor determining the reventilation rate is the fresh gas flow rate [1]. The term low-flow anesthesia is used in a limited sense to describe techniques of inhalation anesthesia with a semi-closed rebreathing system with a rebreathing rate of at least $50 \%$. When modern re-ventilation systems are used, but the fresh gas flow rate is reduced to less than $2 \mathrm{~L} / \mathrm{min}$, low flow anesthesia can be mentioned for most patients.

Foldes, et al. recommended $1 \mathrm{~L} / \mathrm{min}$ fresh gas flow as low flow anesthesia in 1952. In 1974, Virtue defined a technique called "minimal flow" in which the fresh gas low-flow does not exceed $0.5 \mathrm{~L} / \mathrm{min}$. In 1982, Grote, et al. reduced the fresh gas flow to $1 \mathrm{~L} / \mathrm{min}$ after a five-minute 
high flow start-up period. They defended the superiority of low-flow anesthesia due to its ease of application and simplicity and suggested that it be preferred with closed system anesthesia in the presence of sufficient monitoring device measuring oxygen and volatile agent concentrations in the anesthetic gas. Foldes and Duncalf showed that to ensure sufficient denitrogenation, it should be reduced to $1 \mathrm{~L} / \mathrm{min}$ standard fresh gas flow after applying high fresh gas flow for 10 minutes in the beginning before reducing the flow [2].

The fresh gas flow can be adjusted to any value below the minute volume as desired. However, the fresh gas flow should never be less than the losses through patient intake and leaks in the ventilation system. The lower the fresh gas flow, the smaller the amount of gas removed from the system and the higher the re-ventilation rate. If a re-breathing system is used with a fresh gas stream equal to the patient's minute volume, the rate of reinhaled gas will be negligible. All the expired gas of the patient is expelled from the excess gas discharge valve and the patient breathes almost pure fresh gas. When the fresh gas flow is used at $4 \mathrm{~L} / \mathrm{min}$, the re-ventilation rate increases to approximately $20 \%$. When the flow is reduced to $2 \mathrm{~L} / \mathrm{min}$ or below, the re-ventilation rate increases to $50 \%$ or more [2].

During low-flow anesthesia, the accidental lack of gas volume is quickly noticed by the ventilator monitor, as it will cause both the decreasing minute volume and a sudden decrease in the peak and plateau pressures. In case of accidental gas volume shortage, a fresh gas volume must be increased for at least 1-2 minutes to supplement the anesthetic gas volume. Since the temperature and humidity of anesthetic gases are significantly higher in low-flow anesthesia compared to high-flow techniques, the water concentration increases in patient hoses, especially when the operating room temperature is kept low with ventilation. Low-flow anesthesia techniques should be applied provided that appropriate monitoring is available where these methods can be safely applied, alarm limits are carefully adjusted, and alarms become operable as soon as the patient is connected to the ventilation system. Standard anesthesia monitoring electrocardiogram (ECG), blood pressure, pulse oximetry, capnometry, airway pressure, minute volume, inspired oxygen concentration, and anesthetic agent concentration in the inspired gas in fresh gas flows below $1 \mathrm{~L} / \mathrm{min}$ should be monitored with body temperature $[3,4]$.

Although there are many applications for low-flow in the literature, there is no literature for its use in a single lung. In the literature on the same cases, no studies are examining the effect of minimal and lowflow anesthesia on cerebral oxygenation with Near Infra Red Spectroscopy (NIRS). Therefore, we planned to investigate the effect of minimal and low flow applications on hemodynamic parameters, cerebral oxygenation, blood gas values, and gas consumption during single lung ventilation (SLV).

\section{Materials and Methods}

The ASA I-III group, who will undergo an elective thoracic surgery operation in a prospective randomized manner, by obtaining the approval of the Ethics committee (Decision No: 2020/514172/15 Date: 26.02.2020) (Clinical Trials no: NCT04376307) in the operating room of our hospital, It was performed on 60 patients over 18 years of age, of two genders.

During the preoperative examination, the patients were informed about the study, and their written consent was obtained. On the morning of the operation, automatic tests of the anesthesia device (DragerPerseus A500) and anesthesia gas monitor calibration and leak test were performed and the study was started.

The leak test for the ventilator and breathing circuit was repeated for the patient in all operations. The carbon dioxide holder was evaluated in terms of its dryness and color and was changed every day by repeating it at appropriate times. $10 \mathrm{ml} / \mathrm{kg} / \mathrm{hr} 0.9 \%$ sodium chloride perfusion was initiated by establishing venous access from the dorsum of the hand with a 20 gauge cannula in the patients who were taken to the operating table. After cleaning the forehead of the patients, the regional cerebral oxygen saturation $\left(\mathrm{rSO}_{2}\right)$ measuring device NIRS: method and INVOSTM 5100C (Covidien, CO, USA) sensors were placed on the right and left sides of the frontal region, and their baseline values (before sleeping, the room in the mood) recorded. Cerebral oxygen desaturation was accepted as a $20 \%$ decrease in the patient's basal cerebral oxygen saturation value. During the operation, these values were recorded separately on the right and left with the INVOS trend monitor. ECG was performed with $\left(\mathrm{SPO}_{2}\right)$, non-invasive blood pressure (NIKB) monitoring (Drager Infinity $\mathrm{XL}$ ), and recorded at intervals of 15 minutes, starting before anesthesia (basal), post-induction and after intubation. After induction, invasive arterial blood pressure measurements were initiated by inserting a 20 gauge catheter from the radial artery. After induction, arterial blood gas ( $A B G$ ) was taken. Hourly arterial blood gas follow-ups throughout single-lung ventilation and blood gas samples were recorded at the end of one lung.

$1 \mu \mathrm{g} / \mathrm{kg}$ fentanyl (Fentanyl Citrate, Abbott Lab. North Chicago, USA), 2-3 mg/kg propofol (Fresenius) for induction of anesthesia after preoxygenation in spontaneous breathing at $100 \% \mathrm{O}_{2}$ and fresh gas flow at $4 \mathrm{~L} / \mathrm{min}$ for three minutes. and $0.5 \mathrm{mg} / \mathrm{kg}$ rocuronium intravenous (IV) was administered from the road. When muscle relaxation was observed, orotracheal intubation was performed and the patient (Dräger Perseus) was adjusted to have a tidal volume of $4-6 \mathrm{ml} / \mathrm{kg}$, respiratory frequency of $16-18 / \mathrm{min}$, and an I:E ratio of $1: 2\left(\mathrm{EtCO}_{2}\right.$ 35-45 $\mathrm{mmHg}$ ) using an anesthesia device. A tube was 
placed by selective intubation with the help of fiberoptic bronchoscopy. Alarm limits were set as $\mathrm{FiO}_{2} 30 \%$ lower limit, desflurane $10 \%$ vol upper limit, $\mathrm{EtCO}_{2} 45 \mathrm{mmHg}$ upper limit, Paw $5 \mathrm{cmH}_{2} \mathrm{O}$ lower limit, $30 \mathrm{cmH}_{2} \mathrm{O}$ upper limits. NEW absorb $\mathrm{CO}_{2}$ as soda-lime (Sorbole to Berk, Turkey) was used.

In anesthesia maintenance, patients were randomly divided into two groups $(n=60)$. The first group was determined as the low flow $(1 \mathrm{~L} / \mathrm{min})$ desflurane group (Group 1), the second group as the minimal flow (0.5 L/min) desflurane group (Group 2). After the location of the tube was confirmed by fiberoptic bronchoscopy in both groups, single lung ventilation was started. For the first 10 minutes, $4 \mathrm{~L} / \mathrm{min}$ ( $80 \%$ oxygen $+20 \%$ air) 8-10\% Desflurane (Suprane, Baxter, Puerto Rico, USA) was used. Later, $1 \mathrm{~L} / \mathrm{min}$ (80\% oxygen $+20 \%$ air) $4-6 \%$ desflurane (Suprane, Baxter, Puerto Rico, USA) in Group 1; In Group 2, 0.5 L/min (80\% oxygen + 20\% air) (6-8\% desflurane) was applied. During single lung ventilation in both groups, peripheral oxygen saturation, endtidal carbon dioxide level, heart rate (HR), systolic, diastolic, mean invasive blood pressure values, NIRS, tidal volume, respiratory rate, $\mathrm{FiO}_{2}$, fresh gas flow rate, positive end-expiratory pressure (PEEP),(SBP,DBP, MBP) values were recorded at 15 -minute intervals during the time of continuous single-lung ventilation. With the termination of single lung ventilation, a flow of $2 \mathrm{~L} / \mathrm{min}$ was passed and this flow was continued until the end of the case.

10 minutes before the end of the surgery, $4 \mathrm{~L} / \mathrm{min}$ flow and $100 \%$ oxygen were started. ABG analysis was performed at the zeroth of single lung ventilation and then at 1-hour intervals. Particular care was taken not to open the system outside during one-lung ventilation. The amount of desflurane used at the end of the single lung ventilation was recorded by viewing the anesthesia device. Muscle relaxant antagonism was achieved with 2 $\mathrm{mg} / \mathrm{kg}$ of sugammadex in all patients. Gas consumption was monitored and recorded on the monitor.

\section{Statistical Analysis}

The demographic characteristics of the patients and the collected data were entered in $\mathrm{IBM}^{\circ} \mathrm{SPSS}^{\circ}$ (the Statistical Package for the Social Sciences) Statistics version 23. Variables were characterized using mean, maximum, and minimum values, percentages were used for qualitative variables. Normal distributions were reported as mean $\pm S D$, and Student's t-test was used for comparisons between groups. For the analysis of qualitative variables, Pearson's chi-square test, if the group was small, Fisher's exact test was used. Nonparametric continuous variables were recorded as median and range distribution and compared using Mann-Whitney $U$ tests. While $p<0.05$ value was considered statistically significant, values between $p<$ $0.1-p>0.051$ were accepted as close to significance. Data were kept during surgery in all patients. However, since the duration of anesthesia and surgery were not the same in every patient and the number of patients with anesthesia duration exceeding 150 minutes was less than half of all patients $(n=26)$, comparisons between groups were made up to the $150^{\text {th }}$ minute. Besides, the average of the results of some data $\left(\mathrm{SpO}_{2}, \mathrm{HR}, \mathrm{SBP}, \mathrm{DBP}\right.$, MBP, Tidal Volume (TV), EtCo ${ }_{2}$, NIRS-Left, NIRS-Right) recorded during anesthesia was compared between the groups in order not to overlook the situation in patients whose anesthesia duration exceeded 150 minutes.

\section{Results}

$42(70 \%)$ of the 60 patients with an average age of $56.9 \pm 15.3$ (range $21-77$ ) years were male and $18(30 \%)$ were female. The demographic characteristics of the

Table 1: Demographic characteristics of the patients

\begin{tabular}{|c|c|c|c|c|}
\hline & Total & Group $1(n=30)$ & Group $2(n=30)$ & $p$ value \\
\hline Age, year & $56.9 \pm 15.3$ & $55.2 \pm 16.8$ & $58.6 \pm 13.8$ & 0.559 \\
\hline Gender (Y/K), n & $42 / 18$ & $23 / 7$ & $19 / 11$ & 0.260 \\
\hline Height, cm & $169.8 \pm 9.4$ & $171.0 \pm 9.2$ & $168.6 \pm 9.6$ & 0.283 \\
\hline Weight, kg & $77.5 \pm 12.2$ & $77.2 \pm 12.4$ & $77.8 \pm 12.3$ & 0.819 \\
\hline ASA (1/2/3), n & $7 / 24 / 29$ & $5 / 11 / 14$ & 2/13/15 & 0.475 \\
\hline Comorbidity rate, $\mathrm{n}(\%)$ & $29(48.3 \%)$ & $8(26.7 \%)$ & $21(70.0 \%)$ & 0.001 \\
\hline Op type, n (\%) & $\begin{array}{l}31(51.7 \%) \\
19(31.7 \%) \\
10(16.7 \%)\end{array}$ & $\begin{array}{l}15(50.0 \%) \\
9(30.0 \%) \\
6(20.0 \%)\end{array}$ & $\begin{array}{l}16(53.3 \%) \\
10(33.3 \%) \\
4(13.4 \%)\end{array}$ & 0.608 \\
\hline Anatomical lung resection. & $\begin{array}{l}45(75.0 \%) \\
15(25.0 \%)\end{array}$ & $\begin{array}{l}21(70.0 \%) \\
9(30.0 \%)\end{array}$ & $\begin{array}{l}24(80.0 \%) \\
6(20.0 \%)\end{array}$ & 0.371 \\
\hline
\end{tabular}




\begin{tabular}{|l|l|l|l|l|}
\hline Non-anatomical resection. & & & 0.694 \\
& $14(23.3 \%)$ & $6(20.0 \%)$ & $8(26.7 \%)$ \\
& $10(16.7 \%)$ & $7(23.3 \%)$ & $3(10.0 \%)$ \\
& $29(48.3 \%)$ & $15(50.0 \%)$ & $14(46.7 \%)$ & $5(16.7 \%)$ \\
\hline Other & $7(11.7 \%)$ & $2(6.7 \%)$ & $196.3 \pm 69.3$ & 0.107 \\
\hline Side, $\mathbf{n}(\%)$ & $179.5 \pm 77.8$ & $162.6 \pm 83.3$ & $145.5 \pm 63.5$ & 0.155 \\
\hline Left & $134.7 \pm 63.0$ & $124.0 \pm 61.7$ & $175.5 \pm 67.8$ & 0.190 \\
\hline Right & $162.1 \pm 72.5$ & $148.7 \pm 75.7$ & $63.5 \pm 11.6$ & 0.124 \\
\hline Intubation tube length, $\mathbf{n}(\%)$ & $60.9 \pm 22.2$ & $67.0 \pm 11.2$ & $31.9 \pm 12.7$ & 0.211 \\
\hline
\end{tabular}

*Thymectomy with VATS in 3, VATS decortication in 3, chest wall resection in 2, and thoracotomy in 2.

Table 2: Comparison of the groups in terms of first minute physiological condition.

\begin{tabular}{|c|c|c|c|}
\hline & Grup $1(n=30)$ & Grup $2(n=30)$ & p degeri \\
\hline Peripheral oxygen saturation & $98.0 \pm 2.6$ & $97.3 \pm 1.9$ & 0.036 \\
\hline HR & $85.3 \pm 16.5$ & $88.4 \pm 14.2$ & 0.348 \\
\hline $\mathrm{ETCO}_{2}$ & $34.7 \pm 2.8$ & $34.8 \pm 3.1$ & 0.976 \\
\hline Systolic blood pressure & $139.1 \pm 18.3$ & $142.4 \pm 24.0$ & 0.717 \\
\hline Diastolic blood pressure & $81.0 \pm 11.9$ & $88.0 \pm 16.0$ & 0.100 \\
\hline Mean blood pressure & $106.0 \pm 14.0$ & $110.4 \pm 17.3$ & 0.254 \\
\hline $\mathrm{FiO}_{2}$ & $100.0 \pm 0.0$ & $100.0 \pm 0.0$ & 1.000 \\
\hline Tidal volume & $383.3 \pm 25.3$ & $397.6 \pm 28.3$ & 0.041 \\
\hline Respiratory rate & $17.7 \pm 0.7$ & $18.0 \pm 0.3$ & $0.097^{\star}$ \\
\hline PEEP & $5.0 \pm 0.0$ & $5.0 \pm 0.0$ & 1.000 \\
\hline NIRS-Left & $75.0 \pm 10.9$ & $67.8 \pm 8.4$ & 0.013 \\
\hline NIRS-Right & $74.6 \pm 10.9$ & $69.1 \pm 9.5$ & 0.049 \\
\hline $\mathrm{pH}$ & $7.38 \pm 0.4$ & $7.38 \pm 0.3$ & 0.645 \\
\hline $\mathrm{pCO}_{2}$ & $42.7 \pm 5.6$ & $43.1 \pm 4.3$ & 0.451 \\
\hline $\mathrm{PaO}_{2}$ & $182.0 \pm 61.0$ & $151.4 \pm 61.1$ & $0.068^{*}$ \\
\hline $\mathrm{HCO}_{3}$ & $24.8 \pm 1.4$ & $25.1 \pm 1.9$ & 0.917 \\
\hline Lactate & $1.22 \pm 0.42$ & $1.45 \pm 0.57$ & $0.056^{*}$ \\
\hline Carboxyhemoglobine & $1.20 \pm 0.38$ & $1.33 \pm 0.66$ & 0.656 \\
\hline
\end{tabular}

The values indicated with Bold are statistically significant differences. *Although there is no statistically significant difference, there was a slope towards significance (trend toward)

patients are given in Table 1.

There was no statistical difference between the groups in terms of gender, age, height, weight, ASA score, type of operation, intubation tube size, operation side, duration of anesthesia, single lung ventilation duration, operation time, desflurane intake and consumption (Table 1). Comorbidity was found to be statistically more in Group 2 ( $p=0.001)$.

When the zero-minute values were examined, there was no statistical difference between the groups in terms of heart rate, systolic, diastolic, mean arterial blood pressure, EtCO ${ }_{2}, \mathrm{SpO}_{2}, \mathrm{FiO}_{2}, \mathrm{PEEP}, \mathrm{pH}, \mathrm{pCO}_{2}, \mathrm{HCO}_{3^{\prime}}$ and carboxyhemoglobin ( $\mathrm{CoHb})$, while the tidal volume, NIRS-left, and NIRS There was a statistically significant difference in terms of the right (Table 2). Also, there was a statistically significant difference between the groups in terms of respiratory rate, $\mathrm{pO}_{2}$, and lactate $(\mathrm{p}<0.1-\mathrm{p}$ $>0.051)$.

When the perioperative findings were examined, it was found that the heart peak, systolic, diastolic and mean arterial blood pressure did not change between both groups during anesthesia, while $\mathrm{SpO}_{2}, \mathrm{EtCO}_{2}$, and tidal volume were different between the groups and these differences were significant (Figure 1).

It was observed that $\mathrm{SpO}_{2}$ was lower in Group 2 compared to Group 1 after the $15^{\text {th }}$ minute and this difference continued throughout the operation $(p=$ 0.001). It was observed that $\mathrm{EtCO}_{2}$ started to decrease especially after 15 minutes in Group 2 and remained low during anesthesia $(p=0.02)$. It was observed that tidal volume was significantly lower in Group 1 during the entire anesthesia period $(p=0.01)$. 


\section{Tidal Volume}

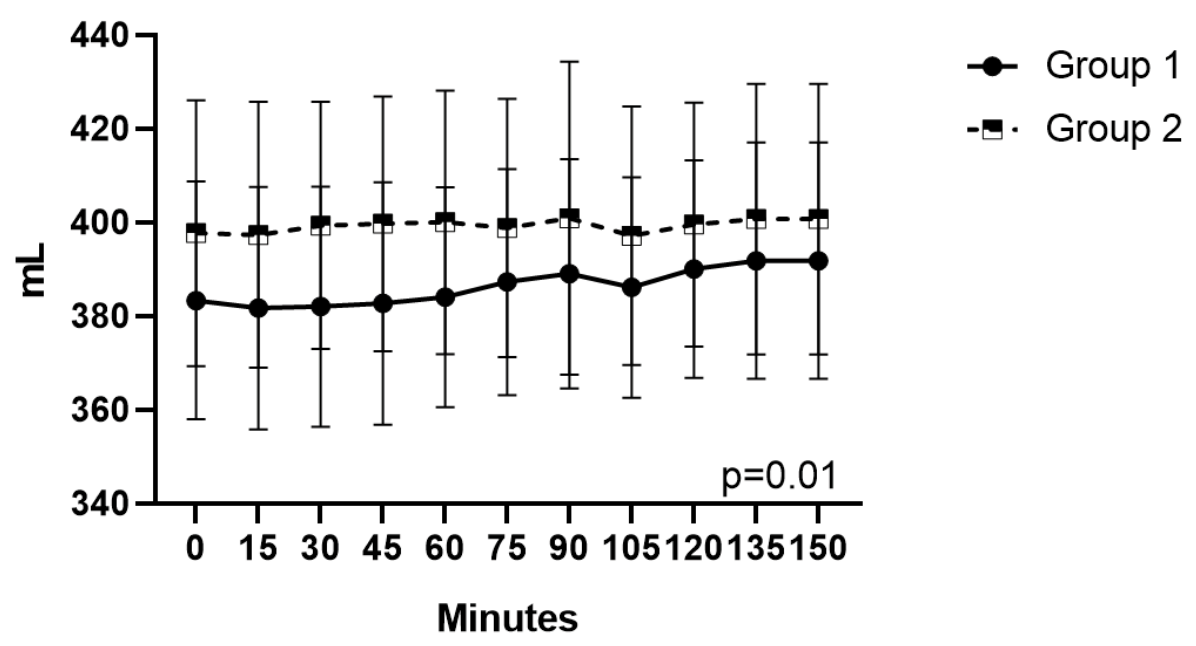

Figure 1: Comparison of the tidal volumes of the groups.

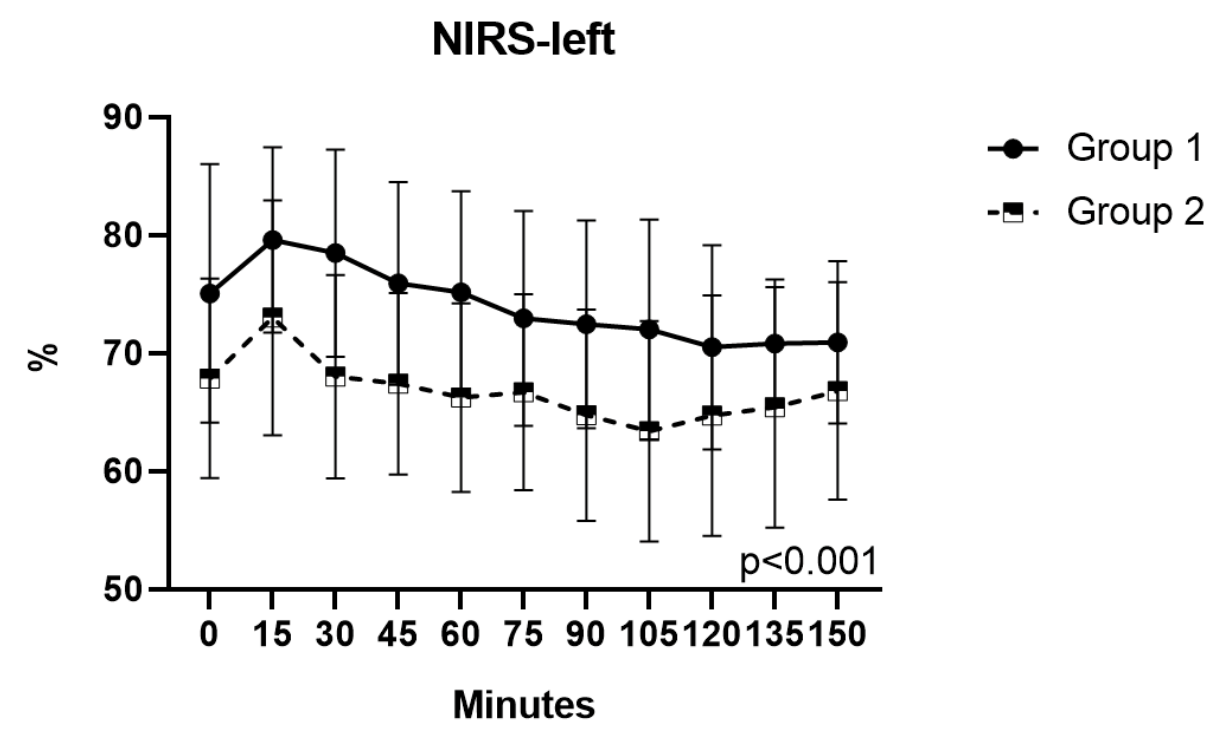

Figure 2: Comparison of the NIRS-left of the groups.

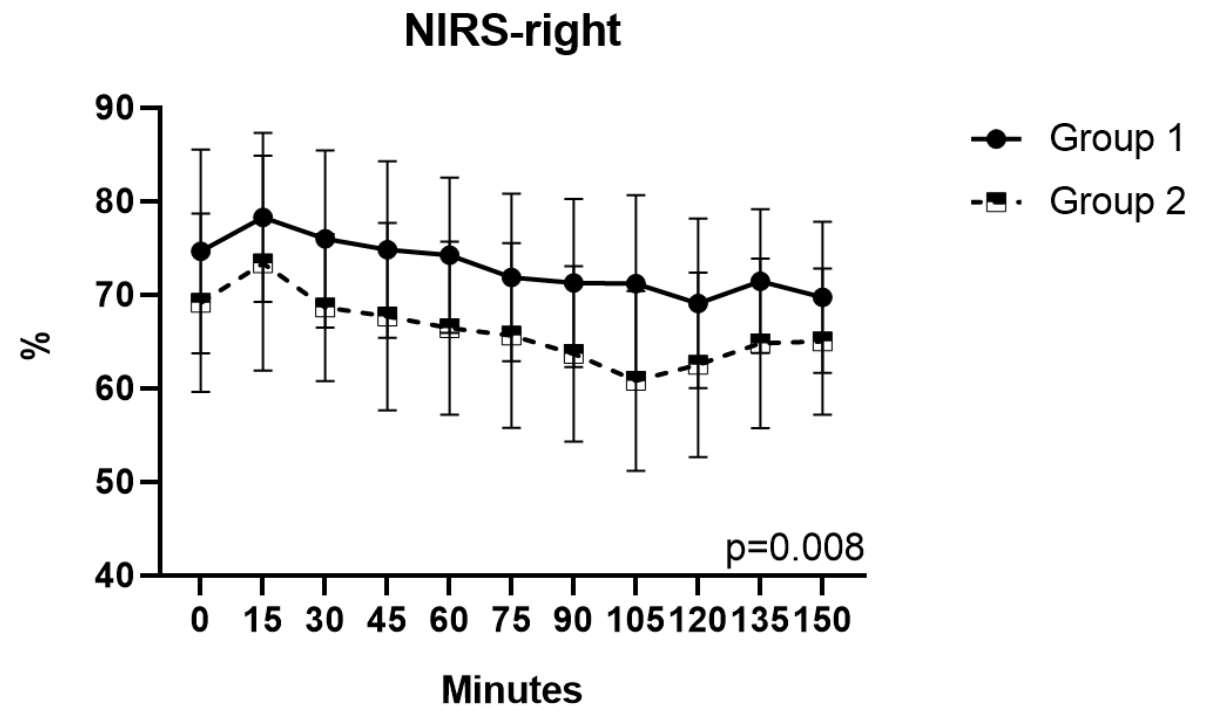

Figure 3: Comparison of the NIRS-right of the groups. 
When the results of blood gas were taken perioperatively were examined, it was seen that there was a statistically significant difference between the groups in $\mathrm{pH}$ and lactate at the $1^{\text {st }}$ hour, $\mathrm{pCO}_{2}$ and $\mathrm{CoHb}$ at the $2^{\text {nd }}$ and $3^{\text {rd }}$ hour, and $\mathrm{HCO}_{3}$ at the $3^{\text {rd }}$ hour (Table 3 ).

When the NIRS was examined separately as left and right, it was found that there was a significant difference between the groups (Figure 2 and Figure 3). It was observed that both right and left NIRS were significantly lower in Group 2 than Group 1 ( $p=0.008$ and $p<0.001$, respectively).

When the averages of the results recorded during anesthesia were compared between the groups, it was found that $\mathrm{SpO}_{2}, \mathrm{EtCO}_{2}$, NIRS-left, and NIRS-right were statistically higher in Group 1 and Tidal Volume was lower (Table 4).

\section{Discussion}

It has been known for years that maintaining anesthesia with low fresh gas flow provides advantages such as anesthetic gas consumption, cost reduction, prevention of environmental pollution, humidification, and heating of gases $[1,5,6]$. Despite all these, discussions and reservations about low-flow anesthesia continue in our country and therefore its use remains limited [7]. Advanced technology re-ventilation systems; the main obstacle to rational use by reducing the current sufficiently is prejudiced about patient safety, especially due to hypoxia.

Table 3: Perioperative blood gas results. ${ }^{*}$

\begin{tabular}{|c|c|c|c|}
\hline & Group $1(n=30)$ & Group $2(n=30)$ & $p$ value \\
\hline \multicolumn{4}{|l|}{ pH } \\
\hline $0 . \mathrm{hr}$ & $7.38 \pm 0.04$ & $7.38 \pm 0.03$ & 0.645 \\
\hline 1.hr & $7.39 \pm 0.04$ & $7.42 \pm 0.05$ & 0.041 \\
\hline 2.hr & $7.37 \pm 0.04$ & $7.39 \pm 0.04$ & 0.110 \\
\hline 3.hr & $7.34 \pm 0.06$ & $7.39 \pm 0.05$ & 0.160 \\
\hline \multicolumn{4}{|l|}{$\mathrm{PCO}_{2}$} \\
\hline $0 . \mathrm{hr}$ & $42.7 \pm 5.6$ & $43.1 \pm 4.3$ & 0.451 \\
\hline 1.hr & $40.4 \pm 5.0$ & $37.9 \pm 5.2$ & $0.051^{\#}$ \\
\hline 2.hr & $40.4 \pm 5.7$ & $36.1 \pm 4.2$ & 0.006 \\
\hline 3.hr & $39.4 \pm 7.5$ & $37.0 \pm 4.7$ & 0.643 \\
\hline \multicolumn{4}{|l|}{$\mathrm{PaO}_{2}$} \\
\hline $0 . \mathrm{hr}$ & $182.0 \pm 61.0$ & $151.4 \pm 61.1$ & $0.068^{\#}$ \\
\hline 1.hr & $131.1 \pm 41.0$ & $119.8 \pm 45.0$ & 0.217 \\
\hline 2.hr & $143.4 \pm 40.8$ & $128.6 \pm 47.9$ & 0.184 \\
\hline 3.hr & $181.4 \pm 38.3$ & $173.6 \pm 47.0$ & 0.428 \\
\hline \multicolumn{4}{|l|}{$\mathrm{HCO}_{3}$} \\
\hline $0 . \mathrm{hr}$ & $24.8 \pm 1.4$ & $25.1 \pm 1.9$ & 0.917 \\
\hline 1.hr & $23.9 \pm 1.4$ & $24.6 \pm 2.1$ & 0.242 \\
\hline 2.hr & $22.7 \pm 1.7$ & $22.7 \pm 1.9$ & 0.859 \\
\hline 3.hr* & $20.8 \pm 1.5$ & $22.2 \pm 1.5$ & 0.041 \\
\hline \multicolumn{4}{|c|}{ Lactate } \\
\hline $0 . \mathrm{hr}$ & $1.22 \pm 0.51$ & $1.45 \pm 0.57$ & $0.056^{\#}$ \\
\hline 1.hr & $1.22 \pm 0.51$ & $1.45 \pm 0.56$ & 0.032 \\
\hline 2.hr & $1.25 \pm 0.45$ & $1.58 \pm 0.61$ & $0.080^{\#}$ \\
\hline 3.hr $r^{*}$ & $1.77 \pm 0.94$ & $1.88 \pm 0.73$ & 0.643 \\
\hline \multicolumn{4}{|c|}{ CoHb } \\
\hline $0 . \mathrm{hr}$ & $1.20 \pm 0.38$ & $1.33 \pm 0.66$ & 0.656 \\
\hline 1.hr & $1.31 \pm 0.54$ & $1.33 \pm 0.66$ & 0.246 \\
\hline 2.hr & $1.08 \pm 0.24$ & $1.61 \pm 0.66$ & 0.001 \\
\hline 3.hr $r^{*}$ & $1.16 \pm 0.53$ & $1.71 \pm 0.80$ & 0.032 \\
\hline
\end{tabular}

*Fourth hour blood gas was not evaluated because there were only ten patients. ${ }^{*}$ third hour assessments were made on 26 patients (10 patients in Group 1, 16 patients in Group 2).

The values indicated with Bold are statistically significant differences. "Although there is no statistically significant difference, there was a slope towards significance (trend toward) 
Table 4: Comparison of the means of some results recorded during anesthesia between groups.

\begin{tabular}{|l|l|l|l|}
\hline & Group 1 $(\mathbf{n}=\mathbf{3 0})$ & Group 2 (n= 30) & p value \\
\hline $\mathbf{S a O}_{2}$ & $\mathbf{9 8 . 0} \pm 2.0$ & $96.4 \pm 1.8$ & $\mathbf{0 . 0 0 1}$ \\
\hline Heart rate & $79.4 \pm 11.9$ & $81.3 \pm 19.1$ & 0.900 \\
\hline ETCO $_{2}$ & $\mathbf{3 4 . 4} \pm \mathbf{3 . 5}$ & $32.1 \pm 4.3$ & $\mathbf{0 . 0 0 7}$ \\
\hline Systolic blood pressure & $116.8 \pm 12.2$ & $112.3 \pm 13.4$ & 0.240 \\
\hline Diastolic blood pressure & $67.7 \pm 9.9$ & $64.5 \pm 8.9$ & 0.404 \\
\hline Tidal volume & $382.9 \pm 24.5$ & $\mathbf{3 9 9 . 2 \pm 2 6 . 8}$ & $\mathbf{0 . 0 2 4}$ \\
\hline MAP & $85.1 \pm 8.5$ & $82.3 \pm 9.5$ & 0.284 \\
\hline NIRS-left & $\mathbf{7 5 . 9 \pm 8 . 1}$ & $67.5 \pm 7.6$ & $<\mathbf{0 . 0 0 1}$ \\
\hline NIRS-right & $\mathbf{7 4 . 6 \pm \mathbf { 8 . 3 }}$ & $67.3 \pm 8.8$ & $\mathbf{0 . 0 0 2}$ \\
\hline
\end{tabular}

The values indicated with Bold are statistically significant differences. "Although there is no statistically significant difference, there was a slope towards significance (trend toward)

This study aims to investigate the effects of low and minimal flow desflurane anesthesia on hemodynamic and blood gas parameters, cerebral oxygenation, and desflurane consumption, and hence their reliability in patients undergoing single lung ventilation.

In the studies of Kazancıoğlu, et al. [8], in which they planned septorhinoplasty with controlled hypotension, maintenance of anesthesia was continued with 0.4 $\mathrm{L} / \mathrm{min}$ or $2 \mathrm{~L} / \mathrm{min}$ fresh gas flow and there was no difference between the groups in terms of hemodynamic parameters, $\mathrm{EtCO}_{2}$, and cerebral oxygen saturation, but desflurane consumption was It was reported that it was low in the current group, and consequently, minimal flow anesthesia management could be used safely.

Elmacıoğlu, et al. [6] applied medium flow (2 L/min), low flow $(1 \mathrm{~L} / \mathrm{min})$, minimal flow $(0.5 \mathrm{~L} / \mathrm{min})$ as fresh gas flow, including 90 patients undergoing cholecystectomy, pyelolithotomy, and thyroidectomy. In their studies, following the results of our study, no difference was determined between the groups in HR, MBP, and endtidal desflurane concentrations, and it was reported that the values were within the physiological limits in all 3 groups. However, unlike us, desflurane consumption was reported to be significantly higher in the low flow group compared to the minimal flow group.

Although Akbaş, et al. [9] compared the effects of normal $(1.5 \mathrm{~L} / \mathrm{min})$ and low $(0.75 \mathrm{~L} / \mathrm{min})$ flow anesthesia on bispectral index scale (BIS) and cerebral oxygenation in 52 morbidly obese patients undergoing laparoscopic sleeve gastrectomy, they were similar in the intraoperative period. Found that cerebral oxygenation was lower in the low flow group after waking up from anesthesia but within physiological limits. As a result, they reported that low-flow anesthesia can be used safely in terms of hemodynamic and respiratory parameters, anesthesia depth, and regional cerebral oxygenation in bariatric surgery.

In single lung ventilation, while perfusion continues in the collapsed lung, lack of ventilation causes an increase in the intrapulmonary shunt from right to left.
The alveolar-arterial oxygen gradient increases and hypoxemia develop with the mixing of non-oxygenated blood from the collapsed lung with oxygenated blood from the ventilated dependent lung [10]. In our literature review, we could not find any studies on the application of low-flow anesthesia, which causes hypoxia, in patients with single lung ventilation who are prone to hypoxemia.

Increased pulmonary vascular resistance, hypoxic pulmonary vasoconstriction, pulmonary arterio-venous shunt, and decrease in partial oxygen pressure with the onset of SLV are the factors that cause cerebral oxygen desaturation [11]. Besides, hemodynamic changes such as an increase in pulmonary artery pressure and a decrease in cardiac output also cause hypoxemia and thus cerebral oxygen desaturation [12]. As a result, we think that SLV causes cerebral oxygen desaturation by reducing both oxygen content and oxygen transport due to cardiac output.

In our study where we applied low $(1 \mathrm{~L} / \mathrm{min})$ and minimal $(0.5 \mathrm{~L} / \mathrm{min})$ flow in single lung ventilation, we found that peripheral oxygen saturation and rightleft cerebral oxygenation values were lower in the minimal flow group in the perioperative period, and at the $45^{\text {th }}$ and $75^{\text {th }}$ minutes in 4 patients. However, we determined that the values in all periods were within the physiological limits, not threatening life. In 2 of these patients, we also found a decrease in peripheral oxygen saturation, which was not reflected in $\mathrm{PaO}_{2}$ in the same period and was also within the physiological limits. At the same time, it was observed that the cerebral oximetry and peripheral oxygen saturation values started to decrease parallel to each other from the perioperative $15^{\text {th }}$ minute. However, in none of the cases, it was determined that the $\mathrm{SpO}_{2}$ value did not fall below $95 \%$ and the $\mathrm{FiO}_{2}$ value below $30 \%$, which is the critical point.

While the possibility of hypercapnia, one of the disadvantages of low-flow anesthesia, is considered in our study, it is interesting that in the minimal flow group, $\mathrm{EtCO}_{2}$ values started to decrease from the $15^{\text {th }}$ 
minute in the perioperative period. However, although it is pleasing that all values are within normal limits (30$35 \mathrm{mmHg}$ ), there is also an opinion that minimal flow is reliable.

Lactate values, which are an indicator of tissue hypoxia and used as complementary to each other with systemic oxygen delivery, were found to be significantly higher in the minimal flow group at the perioperative $2^{\text {nd }}$ and $3^{\text {rd }}$ hours and in the low flow group at the $3^{\text {rd }}$ hour. Tokgöz, et al. [13], in their study, comparing low- and high-flow desflurane anesthesia methods in children stated that lactate was higher in the low-flow group in all anesthesia periods from after intubation to postextubation, following our study. Although publications showing the safe use of low-flow anesthesia with close monitoring [14] were observed in our literature reviews, no studies reporting the effects of minimal flow on lactate were found. The results of our study showed the necessity of careful monitoring of lactate values in anesthesia maintenance with minimal flow.

It is known that in the use of desflurane, carbon monoxide (CO) is formed after its interaction with soda lime, which causes $30 \%$ or more $\mathrm{COHb}$ formation. Therefore, in our study, regular $\mathrm{EtCO}_{2}$ and arterial blood gas measurements were made, and soda-lime changes were made daily and even when needed. In the study conducted by Baum, et al. [15] in which they applied minimal flow with desflurane, an increase in $\mathrm{COHb}$ values was determined after the $45^{\text {th }}$ minute, and in the study conducted by Tokgöz, et al. [14], after the termination of low current and the $10^{\text {th }}$ minute of extubation. In our study, it was observed that the $\mathrm{COHb}$ values started to increase in both groups after the $2^{\text {nd }}$ hour, but the increase was slightly higher in the minimal flow group. It should be kept in mind that the type of inhalation anesthetic used (Desfloran $\geq$ Enfloran $>$ Isofloran $>$ Halothane $=$ Sevoflurane), the dryness of the absorbent, its type, temperature, and the concentration of the anesthetic used are effective factors in the formation of $\mathrm{CO}$ and attention should be paid to these.

During low-flow anesthesia, ventilation pressure may change, negative pressure may occur and tidal volume may decrease. In a study conducted by Tomattr, et al. [16] with adults using $0.5 \mathrm{~L} / \mathrm{min}$ fresh gas flow, they reported that the airway pressure increased and the minute volume decreased by $23 \%$ when passing from high flow to minimal flow, and therefore they adjusted the tidal volume to provide sufficient minute volume. In our study, it was observed that the tidal volume was statistically significantly higher in the group in which we applied minimal flow.

One of the most important advantages of low flow anesthesia techniques is that it provides a reduction in anesthetic consumption and thus cost. Consumption of inhalation agents; depends on fresh gas flow rate, vaporizer setting, and duration of anesthesia. In a study that calculated the consumption using the vaporizer weighing method, desflurane consumption was determined as $0.44 \mathrm{~g} / \mathrm{min}$ in anesthesia given with a flow rate of $0.5 \mathrm{~L} / \mathrm{min}$ [17]. We determined that desflurane consumption, which is quite expensive to use in anesthesia with its low potency and high price, was less in the minimally applied group than in the low-flow group, but the difference was not statistically significant, and both anesthesia management was ideal for this volatile agent in terms of anesthetic agent consumption.

\section{Limitations}

The fact that the research groups were carried out with a relatively small sample can be considered as a limitation of our study. However, there is no study in the literature evaluating the effects on hemodynamics, cerebral oximetry, and blood gas by applying low and minimal flow in single lung ventilation. Therefore, forming study groups with sufficient sample size in future studies will provide stronger results.

\section{Conclusion}

Since low and minimal flow anesthesia applications can be applied safely in SLV patients with an appropriate device and close monitoring, where inspired and expired oxygen and volatile gas concentrations, $\mathrm{CO}_{2}$ and $\mathrm{FiO}_{2}$ levels are continuously monitored and alarm limits can be adjusted as desired, and even the patient should be monitored more closely. It was concluded that it also increased patient safety.

\section{Authors' Contributions}

Study conception and design: FDG, YY, GA; Data acquisition: FDG, YY, GA; Data analysis and interpretation: All authors; Drafting of the article and revising for important intellectual content: All authors; Final approval of the published version: All authors.

\section{Declarations of Interest}

All authors declare that they have no conflicts of interest.

\section{Funding}

None declared.

\section{Acknowledgements}

We thank Necati Citak from Department of Thoracic Surgery, Bakirköy Sadi Konuk Education and Research Hospital, Istanbul, Turkey, for his efforts in statiscal analysis of the data of this study.

\section{References}

1. Baum JA (2001) Low Flow Anaesthesia: The Theory and Practice of Low Flow, Minimal Flow, and Closed System Anaesthesia. ( $2^{\text {nd }}$ edn), Boston: Butterworth-Heinemann.

2. Baum JA, Aitkenhead AR (1995) Low-flow anesthesia. Anaesthesia 50: 37-44. 
3. Baum J, Berghoff M, Stanke HG, Petermeyer M, Kalff $G$, et al. (1997) Low-flow anesthesia with desflurane. Anaesthesist 46: 287-293.

4. Baum JA (1998) Who introduced the rebreathing system into clinical practice? In: Schulte Am Esch J, Goerig M, Proceedings of the Fourth International Symposium on the History of Anaesthesia. Lübeck: Dräger; 441-450.

5. Odin I, Feiss P (2005) Low flow and economics of inhalational anesthesia. Best Pract Res Clin Anaesthesiol 19: 399-413.

6. Elmacıoğlu MA, Göksu S, Kocoglu H, Oner U (2005) Effects of flow rate on hemodynamic parameters and agent consumption in low-flow desflurane anesthesia: An openlabel, prospective study in 90 patients. Current Therapeutic Research 66: 4-12.

7. Hanci V, Yurtlu S, Ayoğlu H, Okyay RD, Erdoğan G, et al. (2010) Effect of low-flow anesthesia education on knowledge, attitude, and behavior of the anesthesia team. Kaohsiung J Med Sci 26: 415-421.

8. Kazancıoğlu L, Batçık Ş, Erdivanlı B, Şen A, Dursun E, et al (2019) Minimal ve yüksek akımlı anestezinin septorinoplasti sırasında serebral oksijenasyon üzerine etkilerinin karşılaştırılması. Turk J Anaesthesiol Reanimation 47: 1216.

9. Akbaş S, Özkan AS (2019) Comparison of effects of low-flow and normal-flow anesthesia on cerebral oxygenation and bispectral index in morbidly obese patients undergoing laparoscopic sleeve gastrectomy: A prospective, randomized clinical trial. Wideochir Inne Tech Maloinwazyine 14: 19-26.
10. Morgan GE, Mikhail MS, Murray MJ, Larson CP (2002) Anesthesia for thoracic surgery. In: Morgan GE, Mikhail MS, Murray MJ, Larson CP, Clinical Anesthesiology. (3 ${ }^{\text {rd }}$ edn), New York: McGraw-Hill Companies, 525-551.

11. Hemmerling TM, Bluteau MC, Kazan R, Bracco D (2008) Significant decrease of cerebral oxygen saturation during single-lung ventilation measured using absolute oximetry. $\mathrm{Br} \mathrm{J}$ Anaesth 101: 870-875.

12. Brinkman R, Amadeo RJJ, Funk DJ, Girling LG, Grocott HP, et al. (2013) Cerebral oxygen desaturation during onelung ventilation: Correlation with hemodynamic variables. Can J Anaesth 60: 660-666.

13. Tokgöz N, Ayhan B, Sarıcaoğlu F, Akıncı SB, Aypar U (2012) Çocuklarda düşük ve yüksek akımlı desfluran kullanarak uygulanan anestezi yöntemlerinin karşılaştırılması. Turk J Anaesth Reanim 40: 303-309.

14. Kılıç F, Avcı O, Duger C, Isbir CA, Kol ÖI, et al. (2018) Evaluation of low and high flow anesthesia methods' effects on perioperative hemodynamics, depth of anesthesia and postoperative recovery in patients undergoing abdominal surgery. Journal of Anesthesia and Surgery 3-29.

15. Baum J, Legat M, Leier M (1997) The Carbon monoxide story. Eur J Anesth 14: 57-58.

16. Tomatır E, Sabuncu C, Şentürk $Y$ (1997) Minimal akım anestezi rutın olarak kullanılabilir mi? Türk Anest Rean Cem Mecmuası 25: 257-262.

17. Horwitz M, Jakobsson JG (2016) Desflurane and sevoflurane use during low- and minimal flow anesthesia at fixed vaporizer settings. Minerva Anesthesiol 82: 180-185. 